\title{
Pengaruh Administrasi Perpajakan, Kualitas Pelayanan Perpajakan, Kesadaran Wajib Pajak, Dan Sanksi Pajak Terhadap Kepatuhan Wajib Pajak Pajak Bumi Dan Bangunan Kecamatan Panekan Kabupaten Magetan
}

\author{
Riyandi Dwi Efendi ${ }^{1}$, Andri Hasmoro Kusumo Broto ${ }^{2}$ \\ ${ }^{1}$ Fakultas Ekonomi, Universitas Merdeka Madiun, Jl. Serayu No. 79, Kota Madiun, 63133 \\ E-mail: rendidwi5439@gmail.com \\ ${ }^{2}$ Fakultas Ekonomi, Universitas Merdeka Madiun, Jl. Serayu No. 79, Kota Madiun, 63133 \\ E-mail: andri@unmer-madiun.ac.id
}

\begin{abstract}
Taxes are the main source of state revenue that can be used for financing, government spending and development. Where tax revenue is the largest domestic revenue. This type of research is a quantitative research. The population in this study amounted to 88 taxpayers and a sample of 88 respondents. Data collection techniques using questionnaires and documentation. The analysis technique uses multiple linear regression. The results obtained indicate that (1) there is a positive and significant effect of tax administration on the compliance of land and building taxpayers in Panekan District, Magetan Regency; (2) There is a positive and significant effect of the quality of tax services on the compliance of taxpayers on land and building taxes in Panekan District, Magetan Regency; (3) There is a positive and significant impact of taxpayer awareness on the compliance of land and building taxpayers in Panekan District, Magetan Regency; (4) There is a positive and significant effect of tax sanctions on the compliance of taxpayers on land and building tax in Panekan District, Magetan Regency; and (5) There is a positive and significant effect simultaneously on tax administration, quality of tax services, taxpayer awareness and tax sanctions on land and building tax compliance in Panekan District, Magetan Regency.
\end{abstract}

Keywords---: tax administration, tax service quality, taxpayer awareness, tax sanctions and taxpayer compliance

\section{I . PENDAHULUAN}

Indonesia merupakan negara yang berkembang dimana pajak memiliki peranan yang sangat penting untuk memenuhi pembiayaan pemerintah dan pembangunan. Salah satu pendapatan Negara yang terbesar dalam menunjang kehidupan Negara adalah pajak. Pajak merupakan sumber utama penerimaan negara yang dapat digunakan untuk membiayai, pengeluaran pemerintah dan pembangunan. Dimana penerimaan pajak merupakan penerimaan dalam negeri yang terbesar. Untuk menjalankan perekonomian pemerintah dan pembangunan maka peranan pajak sangat dibutuhkan.

Kepatuhan yang tinggi dari wajib pajak dibutuhkan untuk kelancaran penarikan pajak. Begitu pula dalam pemungutan Pajak Bumi dan Bangunan juga dibutuhkan kepatuhan yang tinggi dari Wajib Pajak Pajak Bumi dan Bangunan. Kepatuhan wajib pajak adalah suatu keadaan dimana wajib pajak memenuhi semua kewajiban perpajakan dan melaksanakan hak perpajakannya.

Reformasi perpajakan dimulai dari penyempurnaan kebijakan dan sistem administrasi perpajakan sehingga penerimaan pajak dapat dilakukan secara optimal. Perbaikan pelayanan lewat program perubahan, penegak hukum yang implementasinya sanksi dan pelaksana kode etik yang lebih baik harus prioritaskan agar administrasi perpajakan dapat berjalan secara efektif.

Kualitas pelayanan yang baik diharapkan mampu meningkatkan kepatuhan wajib pajak dan pelayanan petugas yang baik akan memberikan kenyamanan bagi wajib pajak. Sehingga meningkatkan kepatuhan wajib pajak dalam memenuhi kewajiban perpajakannya.

Kesadaran wajib pajak merupakan suatu kondisi dimana wajib pajak mengetahui, memahami, menghitung, membayar dan melaksanakan kewajiban pajak dengan sukarela. Semakin tinggi kesadaran wajib pajak maka pemahaman dan pelaksanaan kewajiban perpajakan semakin baik sehingga dapat meningkatkan kepatuhan dalam membayar pajak.

Selain kesadaran wajib pajak, faktor Sanksi pajak diberikan untuk menciptakan kepatuhan wajib pajak dalam melaksanakan kewajiban perpajakannya. Itulah sebabnya penting bagi wajib pajak memahami sanksi-sanksi perpajakan sehingga mengetahui konsekuensi hukum dari apa yang dilakukan ataupun tidak dilakukan. Sanksi diperlukan untuk memberikan pelajaran bagi pelanggar pajak.

Selama ini penerimaan Pajak Bumi dan Bangunan Di Kecamatan Panekan Kabupaten Magetan masih belum memenuhi target dalam membayar pajak bumi dan bangunan, pencapaian penerimaan pajak bumi dan bangunan di Kecamatan Panekan Kabupaten Magetan masih dibawah target yaitu sebesar $74 \%$ yang seharusnya $100 \%$. Sehingga hal ini harus dilakukan usaha agar target penerimaan pajak bumi dan bangunan akan meningkat setiap tahunnya. 
Website : http://ekomaks.unmermadiun.ac.id

\section{METODE PENELITIAN}

\section{A. Jenis Penelitian}

Penelitian ini juga termasuk jenis penelitian asosiatif (hubungan). Menurut Sugiyono (2017), penelitian asosiatif adalah penelitian yang bertujuan untuk mengetahui hubungan antara dua variabel atau lebih. Penelitian ini bertujuan untuk mengetahui pengaruh Administrasi Perpajakan, Kualitas Pelayanan Perpajakan, Kesadaran Wajib Pajak, Dan Sanksi Pajak Terhadap Kepatuhan Wajib Pajak Pajak Bumi Dan Bangunan di Kecamatan Panekan Kabupaten Magetan.

\section{B. Populasi, Sampel dan Teknik Sampling}

\section{Populasi}

Berkaitan dengan populasi yang akan diteliti, terlebih dahulu akan dijelaskan mengenai pengertian populasi. Menurut Sugiyono (2017), populasi adalah wilayah generalisasi yang terdiri dari objek/subjek yang menjadi kuantitas dan karakteristik tertentu yang ditetapkan oleh peneliti untuk dipelajari dan kemudian ditarik kesimpulannya. Populasi dalam penelitian ini meliputi wajib Pajak Bumi Dan Bangunan di Kecamatan Panekan Magetan..

\section{Sampel dan Teknik Sampling}

Berdasarkan data yang peneliti dapatkan wajib pajak Pajak Bumi Dan Bangunan Kecamatan Panekan Magetan per September 2019 berjumlah 719. Karena jumlah populasi yang besar maka perlu dilakukan pengambilan sampel. Menurut Sugiyono (2017), sampel adalah bagian dari jumlah dan karakteristik yang dimiliki populasi tersebut".

Teknik pengambilan sampel dalam penelitian ini adalah berdasarkan rumus Slovin dalam Umar (2019). Berdasarkan pada hasil perhitungan rumus Slovin tersebut, maka responden yang diambil dalam penelitian ini sebesar 88 responden

\section{HASIL DAN PEMBAHASAN}

\section{Analisis Data Penelitian}

\begin{tabular}{ccccc}
\multicolumn{5}{c}{ Tabel 1. Rangkuman Hasil Uji Reliabilitas } \\
Variabel $\mathrm{X}_{1}, \mathrm{X}_{2}, \mathrm{X}_{3}, \mathrm{X}_{4}$, dan $\mathrm{Y}$ \\
\hline \multirow{2}{*}{ No. } & Variabel & $\begin{array}{c}\text { Alpha } \\
\text { hitung }\end{array}$ & $\begin{array}{c}\text { Alpha } \\
\text { Cronbach }\end{array}$ & Keterangan \\
\hline 1. & $\mathrm{X}_{1}$ & 0,787 & 0,6 & Reliabel \\
2. & $\mathrm{X}_{2}$ & 0,810 & 0,6 & Reliabel \\
3. & $\mathrm{X}_{3}$ & 0,813 & 0,6 & Reliabel \\
4. & $\mathrm{X}_{4}$ & 0,825 & 0,6 & Reliabel \\
5. & $\mathrm{Y}$ & 0,804 & 0,6 & Reliabel \\
\hline \multicolumn{4}{r}{ Sumber: Data primer diolah }
\end{tabular}

Pengujian reliabilitas terhadap variabel pendapatan $\left(\mathrm{X}_{1}\right)$, pelayanan pajak $\left(\mathrm{X}_{2}\right)$, pengetahuan perpajakan $\left(\mathrm{X}_{3}\right)$, penegakan hukum pajak $\left(\mathrm{X}_{4}\right)$, variabel kepatuhan wajib pajak pajak bumi dan bangunan $(\mathrm{Y})$ menunjukan bahwa item-item pertanyaan variabel pendapatan adalah reliabel dan layak untuk digunakan dalam penelitian sebab nilai alpha Cronbach variabel administrasi perpajakan sebesar 0,787, kualitas pelayanan perpajakan sebesar 0,810, kesadaran wajib pajak sebesar 0,813 , sanksi pajak sebesar 0,825, dan kepatuhan wajib pajak sebesar 0,804 >0,6.

\section{Pengujian Asumsi Klasik Regresi Linear Berganda}

Suatu hasil dan analisis regresi linear berganda akan dapat dijadikan sebagai dasar pengambilan kesimpulan jika telah memenuhi beberapa asumsi yang disebut dengan asumsi klasik.

a. Uji Normalitas

Berikut ini merupakan hasil pengolahan pengujian normalitas dengan Kolmogorov-Smirnov :

Tabel 2. Kolmogorov-Smirnov

\begin{tabular}{|ll|l|}
\hline & & Unstandardized Residual \\
\hline $\mathrm{N}$ & & 88 \\
Normal Parameters $^{\mathrm{a}}$ & Mean & .0000000 \\
& Std. Deviation & .19453833 \\
Most Extreme Differences & Absolute & .115 \\
& Positive & .115 \\
& Negative & -.077 \\
Kolmogorov-Smimov Z & & .1075 \\
Asymp. Sig. (2-tailed) & & .198 \\
\hline a. Test distribution is Normal. & & \\
Sumber: Data primer diolah & & \\
\end{tabular}


Website : http://ekomaks.unmermadiun.ac.id

Berdasarkan tabel diatas dapat diketahui bahwa nilai signifikan Unstandardized Residual sebesar 0,198 $>\alpha=0,05$, artinya variabel dalam penelitian ini berdistribusi normal.

b. Uji Asumsi Klasik Multikolinearitas

Tabel 3. Coefficients

\begin{tabular}{|ll|r|r|}
\hline \multirow{2}{*}{ Model } & \multicolumn{2}{|c|}{ Collinearity Statistics } \\
\cline { 3 - 3 } & & Tolerance & \multicolumn{1}{c|}{ VIF } \\
\hline 1 & (Constant) & & \\
& administrasi perpajakan & .342 & 2.923 \\
& kualitas pelayanan perpajakan & .104 & 9.650 \\
& kesadaran wajib pajak & .265 & 3.772 \\
& sanksi pajak & .122 & 8.215 \\
\cline { 2 - 3 } & &
\end{tabular}

Sumber: Data primer diolah

Dari tabel diatas dapat diketahui bahwa nilai VIF untuk administrasi perpajakan sebesar 2,923, kualitas pelayanan perpajakan sebesar 9,650 dan kesadaran wajib pajak sebesar 3,772 dan sanksi pajak sebesar 8,215. Karena nilai VIF kurang dari 10, maka dapat disimpulkan bahwa pada model regresi tidak ditemukan adanya masalah multikolinearitas.

c. Uji Asumsi Klasik Heteroskedastisitas

Tabel 4. Correlations

\begin{tabular}{|c|c|c|c|}
\hline & & & Unstandardized Residual \\
\hline \multirow[t]{15}{*}{ Spearman's rho } & \multirow[t]{3}{*}{ Unstandardized Residual } & Correlation Coefficient & 1.000 \\
\hline & & Sig. (2-tailed) & . \\
\hline & & $\mathrm{N}$ & 88 \\
\hline & \multirow[t]{3}{*}{ administrasi perpajakan } & Correlation Coefficient & .067 \\
\hline & & Sig. (2-tailed) & .533 \\
\hline & & $\mathrm{N}$ & 88 \\
\hline & \multirow[t]{3}{*}{ kualitas pelayanan perpajakan } & Correlation Coefficient & .057 \\
\hline & & Sig. (2-tailed) & .595 \\
\hline & & $\mathrm{N}$ & 88 \\
\hline & \multirow[t]{3}{*}{ kesadaran wajib pajak } & Correlation Coefficient & .084 \\
\hline & & Sig. (2-tailed) & .435 \\
\hline & & $\mathrm{N}$ & 88 \\
\hline & \multirow[t]{3}{*}{ sanksi pajak } & Correlation Coefficient & .102 \\
\hline & & Sig. (2-tailed) & .345 \\
\hline & & $\mathrm{N}$ & 88 \\
\hline
\end{tabular}

Sumber: Data primer diolah

Berdasarkan tabel di atas, dapat diketahui korelasi antara administrasi perpajakan dengan Unstandardized residual sebesar 0,533. Korelasi antara kualitas pelayanan perpajakan dengan unstandardized residual sebesar 0,595. Korelasi antara kesadaran wajib pajak dengan unstandardized residual sebesar 0,435. Korelasi antara sanksi pajak dengan unstandardized residual sebesar 0,345. Karena nilai signifikansi korelasi lebih dari 0,05 maka dapat disimpulkan bahwa pada model regresi tidak ditemukan adanya masalah heteroskedastisitas..

\section{Analisa Data Penelitian}

1. Analisis Regresi Linear Berganda

Tabel 5. Hasil Analisis Regresi

\begin{tabular}{|c|c|c|c|c|c|c|}
\hline \multirow[b]{2}{*}{ Model } & & \multicolumn{2}{|c|}{$\begin{array}{c}\text { Unstandardized } \\
\text { Coefficients }\end{array}$} & \multirow{2}{*}{$\begin{array}{c}\begin{array}{c}\text { Standardized } \\
\text { Coefficients }\end{array} \\
\text { Beta }\end{array}$} & \multirow[b]{2}{*}{$\mathrm{t}$} & \multirow[b]{2}{*}{ Sig. } \\
\hline & & B & Std. Error & & & \\
\hline \multirow[t]{5}{*}{1} & (Constant) & -.010 & .189 & & -.054 & .957 \\
\hline & $\begin{array}{l}\text { administrasi } \\
\text { perpajakan }\end{array}$ & .300 & .069 & .296 & 4.384 & .000 \\
\hline & $\begin{array}{l}\text { kualitas pelayanan } \\
\text { perpajakan }\end{array}$ & .296 & .123 & .295 & 2.403 & .019 \\
\hline & $\begin{array}{l}\text { kes } \\
\text { paje }\end{array}$ & .158 & .074 & .163 & 2.127 & .036 \\
\hline & sanksi pajak & .236 & .107 & .249 & 2.201 & .031 \\
\hline
\end{tabular}

a. Dependent Variable: kepatuhan wajib pajak Sumber: Data primer diolah 
Website : http://ekomaks.unmermadiun.ac.id

Koefisien konstanta berdasarkan hasil regresi adalah -0,010, menyatakan bahwa jika menghasilkan nilai $\mathrm{X}_{1}, \mathrm{X}_{2} \mathrm{X}_{3}$ dan $\mathrm{X}_{4}$ adalah nol, maka dari itu nilai $\mathrm{Y}$ adalah sebesar $-0,010$.

Koefisien regresi variabel administrasi perpajakan $\left(\mathrm{X}_{1}\right)$ sebesar 0,300 , kualitas pelayanan perpajakan $\left(\mathrm{X}_{2}\right)$ sebesar 0,296, kesadaran wajib pajak $\left(X_{3}\right)$ sebesar 0,158 , sanksi pajak $\left(X_{4}\right)$ sebesar 0,236 , menunjukkan bahwa setiap kenaikan $\mathrm{X}_{1}, \mathrm{X}_{2}, \mathrm{X}_{3}$, dan $\mathrm{X}_{4}$ sebesar satu satuan akan meningkat nilai kepatuhan wajib pajak bumi bangunan $(\mathrm{Y})$.

\section{Pengujian Hipotesis}

a. Analisa Koefisien Determinasi $\left(\mathrm{R}^{2}\right)$

Uji koefisien determinasi $\left(\mathrm{R}^{2}\right)$ digunakan untuk mengetahui besarnya presentase variasi dalam variabel terikat yang dijelaskan oleh variasi dalam variabel bebas untuk mengetahui seberapa besar pengaruh variabel bebas terhadap variabel terikat. Berikut ini adalah hasil dari pengujian koefisien determinasi $\left(\mathrm{R}^{2}\right)$

\begin{tabular}{|l|c|r|r|r|}
\hline & \multicolumn{4}{|c|}{ Tabel 6. Model Summary } \\
\hline Model & $\mathrm{R}$ & R Square & $\begin{array}{c}\text { Adjusted R } \\
\text { Square }\end{array}$ & $\begin{array}{c}\text { Std. Error of the } \\
\text { Estimate }\end{array}$ \\
\hline 1 & $.933^{\mathrm{a}}$ & .870 & .864 & .19917 \\
\hline
\end{tabular}

a. Predictors: (Constant), sanksi pajak, administrasi perpajakan,

kesadaran wajib pajak, kualitas pelayanan perpajakan

Sumber: Data primer diolah

Berdasarkan Tabel 6, dapat dijelaskan bahwa nilai koefisien determinasi (Adjusted $R$ Square) yang diperoleh adalah 0,864 . Artinya bahwa variasi dan keempat variabel bebas, yaitu administrasi perpajakan, kualitas pelayanan perpajakan, kesadaran wajib pajak dan sanksi pajak memberikan kontribusi pada kepatuhan wajib pajak pajak bumi dan bangunan di Kecamatan Panekan Kabupaten Magetan sebesar 86,4\% sedangkan 13,6\% lainnya dapat dijelaskan oleh variabel lain yang tidak termasuk dalam penelitian, misalnya pengetahuan perpajakan, tarif pajak, dan sikap.

b. Uji t (Parsial)

1. Pengaruh variabel administrasi perpajakan (X1) terhadap kepatuhan wajib pajak pajak bumi dan bangunan (Y)

Sesuai dengan Tabel 5, nilai thitung sebesar 4,384 > t tabel = 1,988 dengan tingkat signifikan 0,000 $<0,05$, artinya bahwa variabel administrasi perpajakan (X1) berpengaruh terhadap kepatuhan wajib pajak pajak bumi dan bangunan di Kecamatan Panekan Kabupaten Magetan.

2. Pengaruh variabel kualitas pelayanan perpajakan (X2) terhadap kepatuhan wajib pajak pajak bumi dan bangunan (Y)

Sesuai dengan Tabel 5 nilai thitung sebesar 2,403 > ttabel = 1,988 dengan tingkat signifikan 0,019<0,05 artinya bahwa variabel kualitas pelayanan perpajakan (X2) berpengaruh terhadap kepatuhan wajib pajak pajak bumi dan bangunan di Kecamatan Panekan Kabupaten Magetan.

3. Pengaruh variabel kesadaran wajib pajak (X3) terhadap kepatuhan wajib pajak pajak bumi dan bangunan (Y) Sesuai dengan Tabel 5 nilai thitung sebesar 2,127 > ttabel = 1,988 dengan tingkat signifikan 0,036 kurang dari 0,05 artinya bahwa variabel kesadaran wajib pajak (X3) berpengaruh terhadap kepatuhan wajib pajak pajak bumi dan bangunan di Kecamatan Panekan Kabupaten Magetan.

4. Pengaruh variabel sanksi pajak (X3) terhadap kepatuhan wajib pajak pajak bumi dan bangunan (Y)

Sesuai dengan Tabel 5 nilai thitung sebesar 2,201 > ttabel = 1,988 dengan tingkat signifikan 0,031 kurang dari 0,05 artinya bahwa variabel sanksi pajak (X4) berpengaruh terhadap kepatuhan wajib pajak pajak bumi dan bangunan di Kecamatan Panekan Kabupaten Magetan.

c. Uji F / Uji Serempak

Uji F digunakan untuk mengetahui pengaruh variabel bebas secara bersama-sama (simultan) terhadap variabel terikat. Apabila menggunakan tingkat signifikan 5\% atau 0,05 dan nilai probabilitas < 0,05 maka dapat dikatakan terdapat pengaruh yang signifikan secara bersama-sama antara variabel bebas terhadap variabel terikat.

\begin{tabular}{|ll|r|r|r|r|r|}
\hline \multicolumn{2}{|c|}{ Tabel 7. Hasil uji F } \\
\hline & $\begin{array}{l}\text { Sum of } \\
\text { Squares }\end{array}$ & Df & $\begin{array}{c}\text { Mean } \\
\text { Square }\end{array}$ & F & Sig. \\
\hline 1 & Regression & 22.080 & 4 & 5.520 & 139.153 & $.000^{\mathrm{a}}$ \\
& Residual & 3.293 & 83 & .040 & & \\
& Total & 25.373 & 87 & & & \\
\hline
\end{tabular}

Sumber: Data primer diolah

Berdasarkan hasil uji F Tabel 7. bisa dilihat F hitung sebesar 139,153 dan nilai signifikan 0,000 > 0,05 maka dapat disimpulkan bahwa variabel administrasi perpajakan (X1), kualitas pelayanan perpajakan (X2), kesadaran wajib pajak 
Website : http://ekomaks.unmermadiun.ac.id

(X3) dan sanksi pajak (X4) berpengaruh terhadap kepatuhan wajib pajak pajak bumi bangunan di Kecamatan Panekan Kabupaten Magetan.

\section{Pembahasan Hasil Penelitian}

Hasil dari pembahasan tentang administrasi perpajakan (X1), kualitas pelayanan perpajakan (X2), kesadaran wajib pajak (X3) terhadap kepatuhan wajib pajak pajak bumi dan bangunan di Kecamatan Panekan Kabupaten Magetan (Y) adalah sebagai berikut:

\section{Pengaruh Administrasi Perpajakan (X1) Terhadap Kepatuhan Wajib Pajak Pajak Bumi Dan Bangunan}

Berdasarkan hasil Uji Parsial (Uji t) variabel administrasi perpajakan (X1) menunjukkan bahwa administrasi perpajakan memiliki pengaruh positif dan signifikan terhadap kepatuhan wajib pajak. Hal tersebut bisa dilihat dari hasil tingkat signifikansi administrasi perpajakan sebesar 0,000 kurang dari 0,05 dan thitung sebesar 4,384 >t tabel = 1,988. Hal ini menunjukkan bahwa variabel administrasi perpajakan signifikan dengan arah positif. Hipotesis pertama (H1) Ada pengaruh administrasi pajak (X1) terhadap kepatuhan wajib pajak pajak bumi dan bangunan (Y) di Kecamatan Panekan, Kabupaten Magetan. Dengan demikian, H1 diterima, bahwa semakin baik pengelolaan administrasi perpajakan maka kepatuhan wajib pajak pajak bangunan juga semakin meningkat.

Penelitian ini juga mendukung penelitian yang dilakukan oleh Syaiful (2016) tentang Pengaruh Kesadaran Wajib Pajak, Administrasi Perpajakan, Dan Sanksi Pajak Terhadap Kepatuhan Wajib Pajak Pajak Bumi Dan Bangunan (Studi Empiris di Kecamatan Koto Tangah Padang). Hasil penelitian ini menunjukkan bahwa variabel Administrasi perpajakan (X2) dengan nilai t hitung $2.928>\mathrm{t}$ tabel 1.980 signifikan $0,04<0,05$. Dari hasil ini dapat disimpulkan bahwa administrasi perpajakan(X2) berpengaruh terhadap kepatuhan wajib pajak pajak bumi dan bangunan(Y), yang mengindikasikan semakin baik administrasi perpajakan maka semakin tinggi tingkat kepatuhan wajib pajak. Bila syarat administrasi perpajakan dipermudah maka akan banyak masyarakat yang akan memenuhi kewajibannya sebagai wajib pajak.

\section{Pengaruh Kualitas pelayanan perpajakan (X2) Terhadap Kepatuhan Wajib Pajak Bumi Dan Bangunan}

Berdasarkan hasil uji parsial (Uji t) variabel kualitas pelayanan perpajakan (X2) menunjukkan bahwa kualitas pelayanan perpajakan memiliki pengaruh positif dan signifikan terhadap kepatuhan wajib pajak. Hal tersebut bisa dilihat dari hasil tingkat signifikansi kualitas pelayanan perpajakan sebesar 0,024 kurang dari $\alpha=0,05$ dan thitung sebesar 2,403 > ttabel = 1,988. Hal ini menunjukkan bahwa variabel kualitas pelayanan perpajakan signifikan dengan arah positif. Hipotesis kedua (H2) ada pengaruh kualitas pelayanan perpajakan (X2) terhadap kepatuhan wajib pajak pajak bumi dan bangunan (Y) Kecamatan Panekan Kabupaten Magetan. Dengan demikian, H2 diterima, bahwa semakin baik kualitas pelayanan perpajakan maka dengan sukarela wajib pajak akan merasa nyaman dan mudah dalam memenuhi kewajibannya membayar pajak bumi dan bangunan.

Hasil penelitian ini juga mendukung penelitian yang dilakukan oleh Herlina (2020) tentang Pengaruh Sanksi, Kesadaran Perpajakan Dan Kualitas Pelayanan Terhadap Kepatuhan Wajib Pajak Bumi Dan Bangunan Di Kabupaten Kerinci. Hasil penelitian menunjukkan bahwa variabel Kualitas Pelayanan dengan nilai t hitung sebesar $2.357>\mathrm{t}$ tabel 1.657 dan signifikan0,020 < 0,05, dapat disimpulkan bahwa kualitas pelayanan (X3) wajib pajak berpengaruh terhadap kepatuhan membayar pajak bumi dan bangunan (Y), yang mengindikasikan supaya dapat meningkatkan kepatuhan seorang wajib pajak maka kualitas pelayanan dalam proses administrasi pajak mau tidak mau harus ditingkatkan. Hal ini dikarenakan kualitas pelayanan merupakan bentuk perbandingan antara pelayanan terhadap wajib pajak selaku konsumen dengan kualitas layanan yang diharapkannya.

\section{Pengaruh Kesadaran Wajib Pajak (X3) Terhadap Kepatuhan Wajib Pajak Pajak Bumi Dan Bangunan}

Berdasarkan hasil uji parsial (Uji t) variabel kesadaran wajib pajak (X3) menunjukkan bahwa kesadaran wajib pajak memiliki pengaruh positif dan signifikan terhadap kepatuhan wajib pajak. Hal tersebut bisa dilihat dari hasil tingkat signifikansi kesadaran wajib pajak sebesar 0,036 kurang dari $\alpha=0,05$ dan thitung sebesar 2,127 $>$ ttabel $=$ 1,988. Hal ini menunjukkan bahwa variable kesadaran wajib pajak signifikan dengan arah positif. Hipotesis ketiga (H3) ada pengaruh kesadaran wajib pajak (X3) terhadap kepatuhan wajib pajak pajak bumi dan bangunan (Y) Kecamatan Panekan Kabupaten Magetan. Dengan demikian, H3 diterima, bahwa semakin tinggi kesadaran wajib pajak maka pemahaman dan pelaksanaan kewajiban perpajakan semakin baik sehingga dapat meningkatkan kepatuhan dalam membayar pajak.

Penelitian ini juga mendukung penelitian yang dilakukan oleh Alam (2017). Pengaruh Sosialisasi Pajak, Kesadaran Wajib Pajak, Dan sanksi Pajak Terhadap Kepatuhan Wajib Pajak Dalam Membayar Pajak Bumi Dan Bangunan Di Desa Baringeng Kecamatan Lilirilau Kabupaten Soppeng. Hasil penelitian menunjukkan bahwa variabel Kesadaran Wajib Pajak (X2) dengan nilai t hitung sebesar 2,391 > 1,661 dengan nilai signifikan 0,019<0,05. Dari hasil ini dapat disimpulkan kesadaran wajib pajak (X2) berpengaruh positif dan signifikan terhadap kepatuhan wajib pajak pajak bumi dan bangunan (Y), yang mengindikasikan wajib pajak tidak akan patuh membayar pajak jika tidak atas dasar sadar diri sendiri. Apabila kesadaran wajib pajak tinggi maka kepatuhan wajib pajak juga tinggi. 
Website : http://ekomaks.unmermadiun.ac.id

\section{Pengaruh sanksi pajak (X4) Terhadap Kepatuhan Wajib Pajak Pajak Bumi Dan Bangunan}

Berdasarkan hasil uji parsial (Uji t) variabel sanksi pajak (X4) menunjukkan bahwa sanksi pajak memiliki pengaruh positif dan signifikan terhadap kepatuhan wajib pajak. Hal tersebut bisa dilihat dari hasil tingkat signifikansi sanksi pajak sebesar 0,031 kurang dari $\alpha=0,05$ dan thitung sebesar 2,201 $>\mathrm{t}$ tabel $=1,988$. Hal ini menunjukkan bahwa variabel sanksi pajak signifikan dengan arah positif. Hipotesis keempat (H4) ada pengaruh sanksi pajak (X4) terhadap kepatuhan wajib pajak pajak bumi dan bangunan (Y) Kecamatan Panekan Kabupaten Magetan. Dengan demikian, $\mathrm{H} 4$ diterima, yang berarti bahwa wajib pajak akan patuh karena wajib pajak berpikir adanya sanksi atau untuk memberikan efek jera bagi pelanggar pajak. Sehingga sanksi pajak dapat meningkatkan kepatuhan wajib pajak dalam membayar pajak pajak bumi dan bangunan.

Penelitian ini juga mendukung penelitian yang dilakukan oleh Herlina (2020) tentang Pengaruh Sanksi, Kesadaran Perpajakan Dan Kualitas Pelayanan Terhadap Kepatuhan Wajib Pajak Bumi Dan Bangunan Di Kabupaten Kerinci. Hasil penelitian menunjukkan bahwa variabel Sanksi (X1) dengan nilai t hitung $5.267>\mathrm{t}$ tabel 1.657 dan nilai signifikansi $0,000<0,05$ dapat disimpulkan bahwa sanksi pajak (X1) berpengaruh terhadap kepatuhan membayar pajak bumi dan bangunan $(\mathrm{Y})$, yang mengindikasikan bahwa dengan adanya sanksi diharapkan adanya peningkatan dalam kepatuhan membayar pajak bumi dan bangunan.

5. Pengaruh simultan Administrasi Perpajakan, Kualitas Pelayanan Perpajakan, Kesadaran Wajib Pajak dan Sanksi Pajak terhadap Kepatuhan Wajib Pajak Bumi dan Bangunan.

Berdasarkan uji statistik F (uji simultan) menunjukkan nilai signifikansi sebesar 0,000. Nilai 0,000 kurang dari 0,05 maka bisa disimpulkan bahwa terdapat pengaruh administrasi perpajakan (X1), kualitas pelayanan perpajakan (X2), kesadaran wajib pajak (X3) dan sanksi pajak (X4) berpengaruh terhadap kepatuhan wajib Pajak Bumi dan Bangunan (Y).

\section{KESIMPULAN}

Berdasarkan pembahasan hasil penelitian dapat ditarik kesimpulan dalam penelitian ini adalah:

1. Ada pengaruh positif dan signifikan administrasi perpajakan terhadap kepatuhan wajib pajak pajak bumi dan bangunan di Kecamatan Panekan Kabupaten Magetan.

2. Ada pengaruh positif dan signifikan kualitas pelayanan perpajakan terhadap kepatuhan wajib pajak pajak bumi dan bangunan di Kecamatan Panekan Kabupaten Magetan.

3. Ada pengaruh positif dan signifikan kesadaran wajib pajak terhadap kepatuhan wajib pajak pajak bumi dan bangunan di Kecamatan Panekan Kabupaten Magetan.

4. Ada pengaruh positif dan signifikan sanksi pajak terhadap kepatuhan wajib pajak pajak bumi dan bangunan di Kecamatan Panekan Kabupaten Magetan.

5. Ada pengaruh positif dan signifikan secara simultan administrasi perpajakan, kualitas pelayanan perpajakan, kesadaran wajib pajak dan sanksi pajak terhadap kepatuhan wajib pajak pajak bumi dan bangunan di Kecamatan Panekan Kabupaten Magetan.

\section{DAFTAR PUSTAKA}

Alam, S. (2017). Pengaruh Sosialisasi Pajak, Kesadaran Wajib Pajak, Dan Sanksi Pajak Terhadap Kepatuhan Wajib Pajak Dalam Membayar Pajak Bumi dan Bangunan Di Desa Baringeng Kecamatan Lilirilau Kabupaten Soppeng. Universitas Islam Negeri Alauddin Makassar, Akuntansi. Makassar: Fakultas Ekonomi dan Bisnis. Retrieved from http://repositori.uin-alauddin.ac.id/6431/1/Syamsu\%20Alam_opt.pdf

Herlina, V. (2020). Pengasuh Sanksi Kesadaran Perpajakan Dan Kualitas Pelayanan Terhadap Keputusan Wajib Pajak Bumi dan Bangunan di Kabupaten Kerinci. Jurnal BENEFITA, 5(2), 252-263. doi:https://doi.org/10.22216/jbe.v5i2.5168

Sugiyono. (2017). Metode Penelitian Kuantitatif, Kualitatif dan R\&D. Bandung: Alfabeta.

Syaiful, R. (2016). Pengaruh Kesadaran Wajib Pajak, Administrasi Perpajakan, Dan Penegakan Hukum Pajak Terhadap Kepatuhan Wajib Pajak Bumi dan Bangunan (Studi Empiris di Kecamatan Koto Tangah Padang). Jurnal Akuntansi, 4(2), 1-18. Retrieved from http://ejournal.unp.ac.id/students/index.php/akt/article/view/2390/1899

Umar, H. (2019). Metode Penelitian Untuk Skripsi dan Tesis Bisnis (11 ed.). Jakarta: PT Raja Grafindo Persada. 